\title{
DERECHO Y VIOLENCIA: REESCRITURAS EN TORNO AL PLURALISMO JURÍDICO
}

A los hombres les disgusta admitir que las "razones" de una y otra parte son equivalentes, esto es, que la violencia carece de razón.

René Girard, La violencia y lo sagrado

\section{Cristóbal Carmona Caldera*}

\begin{abstract}
RESUMEN
Un elemento importante de los conflictos actuales entre el Estado y los pueblos indígenas en nuestro país dice relación con la concepción del derecho positivo como intrínsecamente superior al derecho propio indígena. Esto ha derivado en que éste carezca de un reconocimiento efectivo dentro de nuestro ordenamiento jurídico, lo que a la vez intensifica el estado general de injusticia intercultural en el que aún viven estos pueblos. Por ende, el presente artículo propone una crítica de aquella premisa de superioridad, investigando los fundamentos de autoridad del derecho estatal y proponiendo una nueva narrativa en donde éstos se vinculen inextricablemente con la violencia. Así, se estima, se posibilitaría la apertura del sistema normativo oficial al hecho básico del pluralismo jurídico.
\end{abstract}

\section{PLURALISMO JURÍDICO - LEGALISMO - VIOLENCIA FUNDACIONAL}

\section{Law and violence: rewritings surrounding legal pluralism}

\begin{abstract}
An important element in the current conflicts between the State and the indigenous peoples in Chile is related to the belief that national law is intrinsically above the indigenous peoples own law. This has generated the lack of its effective recognition in our legal system, which in turn intensifies the general state of intercultural injustice that these groups still live in. Therefore, the present article suggests a review of the aforementioned premise of superiority, investigating the foundations of authority of state law, and proposes a new account of these matters, where these are intricately linked to violence. This new account should allow the opening of the official legal system to the basic fact of legal pluralism.
\end{abstract}

\section{LEGAL PLURALISM - LEGALISM - FOUNDATIONAL VIOLENCE}

* Abogado, Investigador del Observatorio Ciudadano y del Programa de Estudios de Antropología Jurídica e Interculturalidad de la Facultad de Derecho de la Universidad de Chile, Santiago de Chile. c.g.carmona@gmail.com

Artículo recibido el 31 de agosto de 2009 y aceptado para su publicación por el Comité Editorial el 26 de octubre de 2009. 


\section{INTRODUCCIÓN}

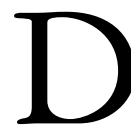

entro de las múltiples aristas a considerar en cualquier análisis básico de las relaciones entre los pueblos indígenas de nuestro país y el Estado hay una que me parece particularmente importante. Me refiero a cómo los problemas de "tierra" -ya sea que se trate del proceso reivindicacionista del pueblo mapuche o de los conflictos socioambientales de las comunidades del norte del país- en parte descansan en una pugna semántica sobre el significado y la amplitud de este mismo significante: mientras que la concepción occidental se remite en lo principal a la tierra efectivamente ocupada para residir por el sujeto, la de los pueblos indígenas comprende además sus lugares ceremoniales, los espacios mítico-religiosos, las áreas de pastoreo, el subsuelo, etc. -lo que técnicamente se conoce como "territorio"- ${ }^{1}$ Esta diferencia, que en la literatura especializada y en el derecho internacional de los derechos humanos ya puede sonar trivial, sirve para distinguir con nitidez la existencia de dos universos normativos, de dos nomos específicos, cuyas fricciones articulan antagónica y subalternamente las relaciones entre ambas culturas. En este sentido, la pugna semántica en torno a la "tierra" no es sino la metonimia de un conflicto mayor, a saber, el que opera entre el derecho propio indígena y el ordenamiento jurídico chileno. ${ }^{2}$

Nadie ignora que, en la actualidad, la mentada antinomia se resuelve fácilmente en una supremacía cuasiontológica del derecho estatal frente al indígena. Dicha narrativa imbrica y da sustento a una serie de elaboraciones legales, doctrinarias y jurisprudenciales que impiden la manifestación del nomos de los pueblos originarios y, consecuentemente, del verdadero reconocimiento de sus derechos. Pues bien, la intención del presente artículo es criticar aquella premisa de superioridad, en la creencia que ello permitiría la apertura del orden legal a una pluralidad normativa, cuestión clave para la consecución de una mayor justicia intercultural. Para esto, empezaré delimitando el campo del problema, revisando los términos actuales en que se estructuran las relaciones entre el derecho estatal y el derecho propio indígena, y determinando la lógica legalista que subyace a dicha estructura (I); luego, de la mano de una interpretación del texto "Ante la ley" de Kafka, exploraré la vacuidad de dicha lógica (II), para terminar el análisis sugiriendo,

${ }^{1}$ Recordemos que el Convenio 169 de la OIT en su art. 13.2 establece que "La utilización del término 'tierras' en los artículos 14 y 15 deberá incluir el concepto de territorios, lo que cubre la totalidad del hábitat de las regiones que los pueblos interesados ocupan o utilizan de alguna otra manera". En este sentido, la Corte Interamericana de Derechos Humanos ha reconocido la importancia para la supervivencia cultural que tiene la tierra para los pueblos indígenas: "La Corte toma en cuenta que la base espiritual y material de la identidad de los pueblos indígenas se sustenta principalmente en su relación única con sus tierras tradicionales". Considerando 131 del Caso Comunidad Indígena Sawhoyamaxa Vs. Paraguay.

${ }^{2}$ Por ello, como lo explica María Salamanca con respecto del $A z M a p u$, la existencia y vigencia del derecho propio indígena genera problemas de fondo para "la teoría del derecho y la antropología jurídica", en tanto "será necesario reconocer la existencia de un derecho que obedece a paradigmas de fondo que son distintos a los occidentales, que en nuestro país ha preexistido al derecho occidental, con el que posteriormente ha coexistido y se ha influenciado". Salamanca, M., "El derecho en la sociedad mapuche: un análisis de acuerdo a los estudios publicados previos”, en Lillo, R. (Coord.), Resolución de Conflictos en el Derecho Mapuche, Universidad Católica de Temuco, Temuco, s/f. 
a partir de una lectura de W. Benjamin, una explicación/narración sustituta en la que la pretendida prioridad epistémica del derecho occidental pierda asidero y se entienda más bien ésta como el resultado de un acto carente de razones y, por lo mismo, violento (III). Al fin, concluiré con una breve reflexión sobre los efectos que dicha sustitución narrativa -0 "redescripción metafórica”, si se quiere seguir a Rorty- tendría para la creación y aplicación de las políticas de reconocimiento indígena (IV).

\section{EL MONISMO JURÍDICO}

A pesar del tiempo transcurrido desde la salida de la Teoría pura del derecho de Kelsen (Reine Rechtslehre, 1934) y de las múltiples revisiones críticas que se han hecho a su obra, basta detenerse un momento para darse cuenta de que el monismo que el jurista austríaco desplegaba en ese entonces -en tanto idea que el derecho sólo existe en la forma de un sistema único, objetivo y universal ${ }^{3}$ todavía es parte importante de la cultura jurídica de nuestro país. Considérense sus palabras en torno al tema:

O bien el sistema jurídico global toma en cuenta los fenómenos jurídicos descritos como constituyendo otro derecho... quedando la unidad restaurada por medio de este sistema global que asume el conjunto o bien los fenómenos del pretendido derecho diferente quedan fuera, no integrados en el sistema, en estado salvaje y no pueden ser calificados como auténtico derecho, siendo considerados todo lo más como subderecho. ${ }^{4}$

Uno podría pensar que lo que hay acá es simplemente una diferenciación formal de aquellas prácticas normativas que se encuentran institucionalizadas $-y$ por tanto integradas al ordenamiento- y aquellas que no. Sin embargo, esta categorización no es ni ingenua ni neutra; en ella va implícita una subordinación fundadora de carácter axiológico-político, de forma tal que la dicotomía dispuesta se ordena jerárquicamente a partir de un modelo en el que uno de los conceptos aparece como "elemento" del otro, en tanto éste último funciona como entidad mayor que lo abarca y define negativamente -lo que Dumont llamó el "englobamiento del contrario" (encompassing of the contrary)-. ${ }^{5}$ En este sentido, la afirmación con la que iniciaba este apartado, relativa a la supervivencia de una lógica similar en Chile, quizás encuentre su ejemplo más señero al considerar el

\footnotetext{
${ }^{3}$ El paradigma de ello se encontraría, para Kelsen, en el establecimiento de un orden legal internacional. Para un interesante estudio de la teoría kelseniana como eslabón fundamental del globalismo jurídico contemporáneo, véase Zolo, D., "Una crítica realista del globalismo jurídico desde Kant a Kelsen y Habermas", en Anales de la cátedra Francisco de Suárez, N 36, 2002, pp. 197-218.

${ }^{4}$ Citado en Sánchez-Castañeda, A., Los orígenes del pluralismo jurídico, p. 475. Documento extraído del sitio <http://www.bibliojuridica.org/libros/4/1855/29.pdf>, visitado el 21 de noviembre de 2008.

5 Dumont, L., "The Anthropological Community and Ideology", en Essays on Individualism. Modern Ideology in Anthropological Perspective, University of Chicago Press, Chicago, 1992, pp. 224 y ss.
} 
hecho de que, a las prácticas alternativas de derecho -estoy pensando principal pero no excluyentemente en el "derecho propio" indígena- se les sigue denominando ${ }^{6}$-cuando no en la letra, sí en el espíritu- como "infra” o "subderecho". Así, en este caso, se parte del Derecho (sobrentendiendo "derecho estatal") como categoría "englobante" para, a continuación, construir conceptualmente las prácticas alternativas de derecho como meras desviaciones ${ }^{7}$ o, peor aún, como situaciones "embrionarias" - "en estado salvaje”, diría Kelsen- del modelo general. Como es obvio, este tipo de maniqueísmo legal obstruye la aprehensión de categorías normativas diferentes, que no caigan en la mera positivización del derecho indígena, ni tampoco en su catalogación subalternante de "costumbre" $-y$, claro, ello sin considerarlo a su vez simplemente como una "vía intermedia" entre ambos conceptos-. Un sucinto análisis del Art. 54 de la Ley 19.253, Ley Indígena, ${ }^{8}$ y su aplicación actual, ayudará en la comprensión de lo que quiero decir.

Contenido en el Párrafo I del Título VII de la Ley, este artículo intenta hacerse cargo del hecho de la pluralidad jurídica, esto es, siguiendo la definición de Boaventura de Sousa Santos, de la coexistencia dentro de un mismo territorio geopolítico de un ordenamiento jurídico estatal, occidentalizado, oficial y, al mismo tiempo, de una pluralidad de ordenamientos jurídicos locales, tradicionales o recientemente desarrollados, no oficiales, de raigambre comunitaria. ${ }^{9}$ Pues bien, de la sola lectura del texto, se desprende que este artículo es poco de lo que puede hacerse cargo. De partida, esta "costumbre" hecha valer entre indígenas de la misma etnia -que, por lo demás, en el proyecto de ley figuraba como "derecho consuetudinario"- $-{ }^{10}$ sólo tendrá valor en tanto no sea incompatible con la Constitución Política de la República. Esto, que a cualquier persona con un mínimo de formación jurídica le puede parecer obvio, se vuelve bastante problemático si, tomando

${ }^{6}$ Acerca del cómo subyace una estructura de dominación al proceso de nombramiento, véase Butler, J., Lenguaje, poder e identidad, Editorial Síntesis, Madrid, 2007.

${ }^{7}$ Eberhard, C., "Algunas implicaciones de los enfoques alternativos. Hacia un nuevo enfoque del derecho a través de sus prácticas”, en El otro derecho, ILSA, No 30, 2003, p. 15. Una cuestión aún por dilucidar es la posibilidad efectiva de tomar las prácticas alternativas "en su originalidad", como quiere el autor.

8 Art. 54: "La costumbre hecha valer en juicio entre indígenas pertenecientes a una misma etnia, constituirá derecho, siempre que no sea incompatible con la Constitución Política de la República. En lo penal se la considerará cuando ello pudiere servir como antecedente para la aplicación de una eximente o atenuante de responsabilidad.

Cuando la costumbre deba ser acreditada en juicio podrá probarse por todos los medios que franquea la ley y, especialmente, por un informe pericial que deberá evacuar la Corporación a requerimiento del Tribunal.

El Juez encargado del conocimiento de una causa indígena, a solicitud de parte interesada y en actuaciones o diligencias en que se requiera la presencia personal del indígena, deberá aceptar el uso de la lengua materna debiendo al efecto hacerse asesorar por traductor idóneo, el que será proporcionado por la Corporación".

${ }^{9}$ Santos, B., La globalización del derecho. Los nuevos caminos de la regulación y la emancipación, Universidad Nacional de Colombia, ILSA, Bogotá, 1999, p. 149.

${ }^{10}$ Ello, eso sí, tomando en consideración que su redacción implicaba una interpretación mucho más restrictiva, toda vez que se aceptaba siempre que "no contravenga texto legal expreso". C fr. Biblioteca del Congreso Nacional, Historia de la ley. Compilación de textos oficiales del debate parlamentario. Ley 19.253, Protección, fomento y desarrollo de los pueblos indígenas, Vol. I, Santiago, Chile, 1997, p. 523. 
en cuenta que la Constitución no es sino la expresión jurídico-normativa del "ser" de una comunidad política de simiente netamente occidental, ${ }^{11}$ uno asume la contradicción que implica el que un sistema jurídico, elemento que es siempre interrogante, respuesta y expresión de una determinada cultura, sea administrado dentro de las estructuras jurídico-culturales de otra, en muchos sentidos contraria a aquella. ${ }^{12}$

Similar situación se aprecia en lo referido al reconocimiento de la "costumbre indígena" en materia penal que contiene dicho artículo, en donde se la circunscribe a un mero "antecedente" para la posible aplicación de un "eximente o atenuante de responsabilidad" -como una especie de las cultural defences del derecho norteamericano-. ${ }^{13}$ Más allá de ciertas excepciones, como el clásico caso de Juana Catrilaf (1953), en el que ésta se ve eximida de responsabilidad penal en el homicidio de una machi por haber obrado bajo el influjo de una "fuerza síquica irresistible" -i.e., su cultura mapuche- ${ }^{14}$ lo que hay acá no es otra cosa que el reducir el valor del "derecho propio" indígena a las "circunstancias personales” de quien cometió el hecho punible; en términos simples, funciona como "excusa". Coherentemente, en los pocos fallos en los que se ha hecho mención explícita

${ }^{11}$ Cfr. Aldunate, E., "Interpretación constitucional y decisión política”, en Revista de Derecho, Universidad Católica de Valparaíso, N XV, 1993-1994, pp. 31-65. Ya LaSalle, en su clásico ensayo "¿Qué es la Constitución?", concluía que en esencia la Constitución de un país es "la suma de los factores reales de poder que rigen en ese país", en el sentido de que "se cogen esos factores reales de poder, se extienden en una hoja de papel, se les da expresión escrita y a partir de ese momento, incorporados a un papel, ya no son simples factores reales de poder, sino que se han erigido en derecho, en instituciones jurídicas, y quien atente contra ellos atenta contra la ley, y es castigado". Citado en Beca Frei, J. P., "La (im)posibilidad de construir un concepto científico de Constitución”, en Revista Ius et Praxis, año 14, No 2, 2008, p. 310.

${ }^{12}$ Un ejemplo interesante, y no tan mediático como otros, es el modo en que los mapuche distribuyen sus bienes después de morir, pues la misma ley indígena en su artículo 18 establece que la sucesión de las tierras indígenas comunitarias se sujetará a la materia que cada etnia tenga en materia de herencia, y en subsidio por la ley común. Esto, como explica Rodrigo Lillo, puede producir problemas que terminarían con la prevalencia del derecho positivo sobre el $A z M a p u$ : "Conforme a este procedimiento, es posible que a los hijos, herederos universales el primer orden de sucesión, que en la ley chilena excluyen a todos los otros herederos (artículos 951 y 988 del Código Civil) no se les adjudique ningún bien, lo que atenta directamente contra el derecho de propiedad (sobre el derecho real de herencia) que, según el Código Civil, nace para el heredero al momento de la muerte". Lillo, R., "Pluralismo jurídico en Chile. Formulando un marco teórico para una investigación empírica”, en Lillo, R. (Coord.), op. cit., p. 110. Por las mismas razones fue que, en un análisis del art. 246 de la Constitución colombiana, el que establece que los pueblos indígenas pueden ejercer funciones jurisdiccionales "siempre que no sean contrarios a la Constitución y leyes de la república", la Corte Constitucional de ese país resolvió, en su sentencia T-349/96, que si bien la Constitución se refiere de manera general a "la Constitución y la ley" como parámetros de restricción, resulta claro que no puede tratarse de todas las normas constitucionales y legales; de lo contrario, el reconocimiento a la diversidad cultural no tendría más que un significado retórico".

${ }^{13}$ Como explica Carnevali, "Es requisito para esta clase de delitos que la conducta se desarrolle por alguien perteneciente a una cultura minoritaria, la que estima que el comportamiento desplegado no es delito dentro de su esfera cultural, ya sea porque es atípico, justificado o exculpado, pero que, sin embargo, sí lo es dentro del sistema penal de la cultura mayoritaria. O, siendo delitos en ambas culturas, tienen un tratamiento penal diverso". Carnevali, R., "El multiculturalismo: un desafío para el Derecho penal moderno", en Política Criminal, No 3, 2007. A-6, p. 1-28. [http://www.politicacriminal.cl].

${ }^{14}$ En Revista de Derecho y Jurisprudencia y Gaceta de los Tribunales, Año 1955, T. LII, $2^{\mathrm{a}}$ parte, sec. $4^{\mathrm{a}}$, p. 85 y ss. 
al contexto cultural indígena, la referencia al artículo en comento ha sido más bien periférica, ${ }^{15}$ utilizándose antes la hipótesis del "error de prohibición", a saber, que en la comisión del hecho típico y antijurídico falta la conciencia de la ilicitud del proceder (culpabilidad), debido, entre otras cosas, a la procedencia cultural del acusado. ${ }^{16}$ Uno podría pensar que con la entrada en vigencia del Convenio 169 de la OIT esta estrechez e impermeabilidad del derecho estatal a otros referentes cognitivo-normativos podría verse subsanada, principalmente en virtud de lo dispuesto en los artículos 9 y 10 del mismo. Aun cuando en forma personal me parece que, aparte del tópico de la jurisdicción indígena (Art. 9.1), ${ }^{17}$ la distancia entre la Ley Indígena y el Convenio 169 en estos temas no es mucha, aún así digo, la exégesis que de éste hizo el Tribunal Constitucional en su fallo Rol 309 del 2000, ${ }^{18}$ restringe fuertemente cualquier pretensión de "progresividad" en la interpretación del Art. 54 de la ley, por cuanto valida la justificación legislativa y la aplicación judicial existente, confinando a la costumbre a ser sólo uno más de los

${ }^{15}$ Cfr. Oliva, S., "Reforma procesal penal y ley indígena”, en Stippel, J. (Ed.), Reforma a la justicia: una visión de los derechos indígenas, Ministerio de Justicia: Proyecto Reforma Judicial de la Sociedad para la Cooperación Técnica Alemana GTZ-Chile: Ministerio de Planificación, Programa Orígenes, Santiago, 2004, pp. 44 y ss. En la mayoría de las sentencias que citan el Art. 54 de la Ley Indígena no hay una decisión basada en él, sino que se usa como elemento anexo para justificar una determinada decisión respecto a la actuación de una persona; así, por ejemplo, dentro de la atenuante de "irreprochable conducta anterior" (11 No 6, Código Penal), es en la causa RUC 0500418571-6, Tribunal Oral en lo Penal (TOP) Stgo. 12/06/2006.

${ }^{16}$ Cfr., sentencia en causa RUC 020075104-1, de 11/06/2004, del TOP Temuco, y también, aunque no de forma tan directa, en la sentencia en causa RUC 0400178619-4, de 30/07/2005, del TOP Villarrica. Una sentencia interesante a este respecto es la dictada por el TOP de Calama en causa RUC 0600900213-6, de 06/10/2007, en la que se rechaza explícitamente la hipótesis del "error de prohibición", en el sentido de que las imputadas sabían perfectamente que la acción que estaban realizando era ilícita, por lo que el tribunal recurre al eximente de responsabilidad contenido en el art. $10 \mathrm{~N}^{\circ} 10$, esto es, el ejercicio legítimo de un derecho: "En consecuencia, las acusadas actuaron creyendo equivocadamente que se encontraban amparadas en la causal de justificación del artículo $10 \mathrm{~N}^{\circ} 10$ del Código Penal, por el ejercicio legítimo de un derecho, lo que obsta a la existencia de la conciencia de la ilicitud de su conducta, por lo que debe entenderse que su actuación en el hecho del juicio, con ser una acción típica y antijurídica, no es culpable, toda vez que falta el elemento de la conciencia de la ilicitud de su proceder, lo que en la especie, en relación a lo obrado por las acusadas, no se dio, por lo que al no existir la culpabilidad, componente aquella de ésta, no hay delito". Considerando $18^{\circ}$. Sin embargo, como se puede notar de este mismo párrafo, la argumentación es un tanto confusa, pues dice que "actuaron creyendo erróneamente", lo que implicaría, en cierto sentido, que sería también error de prohibición. Al respecto, Barrientos, I., "Licitud del uso y porte de la hoja de coca: un caso de invocación y aplicación judicial del derecho internacional de los derechos humanos", en Defensorías Regionales. Minuta Regional, $\mathrm{N}^{\circ} 1$, mayo, 2008.

${ }^{17}$ Ahora bien, este artículo contendría dos cláusulas de salvaguarda, cuales serían el sistema jurídico nacional y los derechos humanos. Como observa Rodrigo Correa, lo que hacen estas cláusulas es que vendrían a descartar cualquier conflicto de constitucionalidad sacrificando para ello la densidad normativa de la disposición: "En otras palabras, lo importante no es preguntarse si el 1 del artículo 9 es contrario a la Constitución, sino más bien en qué extensión dicha disposición resulta aplicable después de considerar las disposiciones constitucionales pertinentes". Correa, R., "Informe de Constitucionalidad Convenio 169 sobre pueblos indígenas y tribales en países independientes, de la OIT”, en Comisión de Verdad Histórica y Nuevo Trato, Subcomisión de Legislación, 2002.

${ }^{18}$ Considerando $50^{\circ}$ y siguientes. 
elementos comprendidos en "la situación personal del participante", que el juez debiese considerar al momento de fallar el caso en cuestión.

No se requiere un análisis hermenéutico demasiado acucioso para darse cuenta de que la base axiológica que se describió al comienzo -el monismo jurídico- determina el contenido, la aplicación e incluso la interpretación posterior del mentado artículo. En otras palabras, aún hoy no hay un espacio al interior de la lógica-limpia, aséptica, necesaria- del derecho positivo que permita una comprensión del "derecho propio" indígena fuera del esquema unilineal "ley-costumbre".

Ahora, creo, hay algo peculiarmente fetichista en esta concepción del derecho. Al igual que en el clásico ejemplo de Marx, donde el "ser rey" era un efecto de relaciones sociales entre un rey y sus súbditos, pero que -en razón del proceso de inversión fetichista- los participantes de ese vínculo social creían que daban al rey un tratamiento real porque éste era ya en sí, fuera de su relación con ellos, un rey, acá se considera al derecho, no como si fuese un efecto estructural de una red de relaciones entre elementos sociales contingentes, sino como si perteneciese a ésta fuera de su relación con los demás elementos, como si fuese ya, en sí, “derecho". En consecuencia, este derecho "dado” se presenta ante sus pares como un sistema universal y neutral, cuyos fundamentos de autoridad se ven revestidos de un halo de objetividad explicada como obviedad -lo que es lo mismo que decir que no se explica en absoluto-; en otras palabras, se piensa el derecho positivo como trascendente -en sentido kantiano-, originario y válido en sí mismo, independiente de cualquier referencia a la praxis y, principalmente, de todo elemento axiológico-político, en tanto se entiende éste último como emparentado a las nociones de arbitrariedad y poder. Se repite acá, aunque en una forma si se quiere más "estructural", la distinción entre derecho, como entidad neutra y objetiva, y política, como "hijo descontrolado de intereses e ideologías", que Judith Shklar denominó como legalismo, ${ }^{19}$ y cuya influencia se extiende inclusive a áreas como el derecho internacional público, ${ }^{20}$ o a la lógica operativa de organismos propiamente políticos. ${ }^{21}$ Esta postura, tan política como cualquier otra, cumple una función ideológica básica, ${ }^{22}$ en cuanto dota de necesidad e inevitabilidad a un sistema tremendamente frágil y contingente, intensificando así la impermeabilidad del orden jurídico chileno a aceptar fuentes diversas de derecho y, con ello, impidiendo el pleno ejercicio del derecho de los pueblos indígenas -nacional e internacionalmente reconocido- a mantener y desarrollar su cultura con autonomía.

${ }^{19}$ Acá, "la política es considerada no sólo como algo aparte del derecho, sino que inferior al derecho. El derecho tiende a la justicia, mientras que la política mira solamente a la conveniencia. El primero es neutral y objetivo, mientras la segunda es el hijo descontrolado de intereses e ideologías”. Shklar, J., Legalismo, Omeba, Buenos Aires, 1968, p. 115.

${ }^{20}$ Reyes Moreno, L. E., "Forma y sustancia en la argumentación en derecho internacional público", en Revista de Derecho, Universidad Austral, Vol. XX, N 1, julio 2007, pp. 149-173.

21 Atria, F., “¿Qué desacuerdos valen? La respuesta legalista”, en Revista Ius et Praxis, Año 8, No 1, 2002, pp. 419-427.

${ }^{22}$ En el preciso sentido acuñado por J.B. Thompson de "significado al servicio del poder". Thompson, J.B., Ideology and Modern Culture, citado en Larraín, J., Modernidad Razón e Identidad en América Latina, Ed. Andrés Bello, Santiago, 1996, p. 44. 
De aquí, entonces, lo perentorio de terminar con esta ideología. Y, en mi opinión, ello pasa, antes que todo, por un gesto de constricción: en orden a posibilitar la apertura requerida, es imperativo que el derecho estatal acabe con su propia intelección como referente central y trascendental de todo derecho. ${ }^{23}$ Por tanto, a continuación me abocaré a tratar de producir dicha constricción, argumentando cómo la autoridad - de la ley, del derecho, del Estado- no se basa sino en el mero hecho fáctico de su autoridad, desafiliando su "invención" - en el sentido de la Erfindung nietszcheana- ${ }^{24}$ de toda significación trascendente o, siquiera, racional -lo que Pascal llamó "el fundamento místico de su autoridad”- ${ }^{25}$ y vinculando su nacimiento, su fundación, a un acto puramente político, carente a priori de las razones normativas que argüirá a posteriori para la legitimación de ese mismo acto.

\section{EN LA LEY}

Žižek, refiriéndose a las relaciones entre la fantasía y "lo real”, sugirió alguna vez que la creencia, lejos de ser un estado "íntimo", se materializaba siempre en nuestro estado social efectivo; es la creencia la que sostiene la fantasía que regula la realidad social y,

${ }^{23}$ Obviamente, esto no se traduce en una convivencia horizontal de los distintos sistemas normativos que operan dentro del espacio administrativo del Estado. Todo derecho de las comunidades indígenas, en Chile y gran parte de Latinoamérica, debe ser entendido en una relación de subalternidad con la sociedad occidental; pero al menos ahora, esta hegemonía sería por razones puramente fácticas -conquista, violencia-, bastante más difíciles de sostener argumentativamente en un Estado democrático que la obvia superioridad intrínseca de un derecho sobre otro. Llegado este punto, es relevante preguntarse si tal "apertureidad" del derecho positivo para con los sistemas normativos indígenas no es sino un regreso subrepticio a aquella "unidad del sistema jurídico" kelseniana. Este es un tema demasiado complejo y específico como para detenernos en él, pero me parece que ello dependerá, principalmente, de la capacidad (no obligatoria) que tengan los pueblos indígenas para desarrollar lógicas normativas propias, contrarias al derecho positivo. Una serie de reflexiones al respecto se encuentran en Hubner, R., Martínez, J.C., Lachenal, C. y Ariza, R. (Coord.), Hacia sistemas jurídicos plurales. Reflexiones y experiencias de coordinación entre el derecho estatal y el derecho indígena, Konrad Adenauer Stiftung, Bogotá, 2008. Particularmente interesante para el tema en cuestión es el ensayo de Eliza Cruz, "Principios generales del derecho indígena", pp. 29-50.

24 "Para Nietszche la invención -Erfindung-es, por una parte, una ruptura y, por otra, algo que posee un comienzo pequeño, bajo, mezquino, inconfesable. Este es el punto crucial de la Erfindung. Fue debido a oscuras relaciones de poder que se inventó la poesía. Igualmente, fue debido a oscuras relaciones de poder que se inventó la religión. Villanía, por tanto, de todos estos comienzos cuando se los opone a la solemnidad del origen tal como es visto por los filósofos". Foucault, M., La verdad y las formas jurídicas. Cinco conferencias dictadas en la Universidad de Río de Janeiro entre los días 21 y 25 de mayo de 1973. Recurso electrónico, extraído del sitio <www.inicia.es> (sitio visitado el 13 de septiembre de 2008), p. 6.

25 "La costumbre -decía en sus Pensées- constituye toda la equidad, sin más razón que la de ser recibida; es el fundamento místico de su autoridad. Quien la refiere a su principio la aniquila”. Esta cita se encuentra tanto en Žižek, S., “¿Cómo inventó Marx el síntoma?”, en Žižek, S. (comp.), Ideología. Un mapa de la cuestión, FCE, Buenos Aires, 2008, p. 354, como en Derrida, J., "El derecho a la justicia”, en Fuerza de Ley. 'El fundamento místico de la autoridad', Tecnos, Madrid, 2002, p. 29. Ahora, este último refiere la autoría de Pascal a Montaigne. 
en cuanto se pierde la creencia, la trama de la realidad social se desintegra. ${ }^{26}$ En este sentido -observaba el autor esloveno-, el llamado "universo de Kafka" no es una mera "imagen-fantasía de la realidad social”, una "exageración”, sino, al contrario, "es la puesta en escena de la fantasía la que actúa en plena realidad social: todos sabemos que la burocracia no es todopoderosa, pero nuestra conducta 'efectiva' en presencia de la maquinaria burocrática está ya regulada por una creencia en su omnipotencia”. ${ }^{27}$

Teniendo en cuenta lo anterior, quizás sea bueno partir recordando -o más bien jugando con- el breve cuento de Kafka, "Ante la Ley” (Vor dem Gesetz), ${ }^{28}$ aparecido en el penúltimo capítulo - "En la catedral”- de su novela El proceso (1925). Esta pequeña parábola comienza de una manera bastante singular: "Ante las puertas de la ley hay un guardián”. Curioso esto que se vigile el acceso a la Ley, especialmente si -siguiendo literalmente el título del texto- el sujeto que recurre a ella (en este caso un campesino) se sitúa "ante” la Ley para usarla o ponerla en movimiento; más extraño aún si, de acuerdo a la doctrina moderna del derecho, los individuos están dotados de un derecho subjetivo, un poder para exigir algo a alguien en virtud de las normas del ordenamiento jurídico, por ejemplo, para exigir la acción del órgano jurisdiccional. Sin dejar de ser correcta, esta aserción -como cualquier otra- no cierra tan fácilmente. De partida, no se debe olvidar que, por ejemplo, ya en el examen de imputabilidad "aquello que en el discurso jurídico se convertirá en sujeto de derecho, es antes objeto de este discurso. Únicamente en virtud de ello puede transformarse después en sujeto", ${ }^{29}$ como explica Jan M. Broekman. Pues bien, esta alternancia entre ser-sujeto y ser-objeto de derecho, no se agota en dicho campo de análisis, sino que imbrica todo el cuerpo de la Ley y se resuelve en la primacía que ostenta esta última figura en la estructura jurídica, en cuanto necesidad de una mediación institucional para la existencia de un individuo "con derechos". Aquel sentido teológico-escatológico de la Ley como fin trascendente, se vuelve ahora, así, inmanente. "El tribunal [la justicia] no quiere nada de ti. Te toma cuando llegas y te despide cuando te vas", dirá el sacerdote en el referido capítulo de El proceso, luego de comentar el texto que acá se examina. Por ende, uno como sujeto no está simplemente “ante-la-Ley", sino ocupa esa posición porque, primero que todo, está "en-la-Ley”. En una afirmación típicamente romántica, Novalis exclamaba que sólo la Poesía era la absoluta realidad (die Poesie ist das ächt absolut Reelle); si permutamos el sujeto de la oración por la ley o el derecho, se tendrá una buena idea de lo que se quiere decir.

Dicho esto, volvamos a esa singular presencia que resguarda la Ley. Recordemos que, ante las miradas furtivas del campesino hacia la puerta (abierta) de la ley, el guardián le realiza una advertencia:

26 Žižek, S., “¿Cómo inventó Marx el síntoma?”, p. 353 y 354.

${ }^{27}$ Íd., p. 353.

${ }^{28}$ Este texto Kafka lo publicó por separado en la revista semanal judía Selbstwehr (1915), y en su libro de cuentos Un médico rural (1919). Utilizo acá la traducción de Francisco Zanutigh Núñez, aparecida en Kafka, Franz, “Ante la ley”, en Relatos completos, Losada, Barcelona, 2006, p. 212-214; las divergencias, entre corchetes, son de la traducción libre de Almut Schilling.

${ }^{29}$ Broekman, Jan M., Antropología y derecho, Ed. Civitas, Madrid, 1993, p. 259. 
Si tanto te atrae, intenta entrar a pesar de mi prohibición. ${ }^{30}$ Soy poderoso, y soy solamente el último [el primero, de rango más bajo] de los guardianes, pero ante la puerta de cada una de las sucesivas salas hay guardianes cada vez más poderosos; yo mismo no puedo soportar la vista del tercer guardián.

Ahora, si, como se viene argumentando, el individuo siempre está en-la-Ley, ya no podemos considerar a esta serie de guardianes como meros elementos accesorios o trabas externas (culturales, sociales, económicas) que impiden el acceso a la justicia, sino como seres inherentes (auxiliares) a ésta, que con su sola presencia -su puro resguardar-ya están aplicando el derecho. Pero nótese, dicha "aplicación" no es inocua. Como lo advirtió Derrida, si se considera en su traducción al inglés, aplicar el derecho, to enforce the law, hace siempre referencia a la fuerza que, desde el interior, nos recuerda que el derecho es siempre una fuerza autorizada, una fuerza que se justifica o que está justificada al aplicarse, incluso si esta justificación puede ser juzgada desde otro lugar como injusta. ${ }^{31}$ Ciertamente hay leyes que no se aplican, pero no hay una ley sin aplicabilidad, y no hay aplicabilidad, o enforceability de la ley, sin fuerza, sea ésta directa o no, física o simbólica, exterior o interior. ${ }^{32}$ En el caso de los guardianes, dicha fuerza se encuentra autorizada, refrendada en su actuar, por aquel brillo que apenas si se deja ver detrás de ellos, por aquel "resplandor que, inextinguible, sale por [emana de] la puerta de la ley".

El problema es que nadie parece estar autorizado para ponerse en presencia de la fuente de dicha luminosidad. El campesino, como todo héroe kafkiano -sea agrimensor, ejecutivo de un banco o hijo metamorfoseado en insecto-, ansía llegar a la ley, ser parte de ese orden mayor, o acaso tan sólo comprenderlo; el campesino, como todo héroe kafkiano, nunca realiza su expectativa. Muere angustiado ante la puerta de la ley, esperando contemplarla, y sabiendo que dicha puerta era sólo para él: "A nadie se le habría permitido el acceso por aquí, porque esta entrada estaba destinada exclusivamente para ti. Ahora voy y la cierro”, dice el guardián. En este caso, como en una aporía eleática, el movimiento es imposible, ${ }^{33}$ y uno no puede dejar de recordar aquel sendero del que hablaba Kafka en El castillo (1922): "Porque ese camino, esa calle principal de la aldea,

${ }^{30}$ Es curioso notar que en la traducción del texto que realizó Borges, publicada en la revista El hogar en 1938, suprimió completamente esta frase.

${ }^{31}$ Derrida, J., "El derecho a la justicia”, p. 15.

32 Íd., p. 16.

${ }^{33}$ Es sabido que esta referencia entre Zenón de Elea y Kafka es dada por Borges en varios textos, pero especialmente en "Kafka y sus precursores", Obras Completas, Emecé, Buenos Aires, 2007, Tomo II, pp. 107109. Ahora, me parece completamente pertinente lo enunciado por Sábato con respecto a las similitudes del propio Borges con Kafka, en las que Zenón aparecería ligado antes al primero que al judío-alemán: "Si se comparan algunos de los laberintos de Ficciones con los de Kafka, se ve esta diferencia: los de Borges son de tipo geométrico o ajedrecístico y producen una angustia intelectual, como los problemas de Zenón, que nacen de una absoluta lucidez de los elementos puestos en juego; los de Kafka, en cambio, son corredores oscuros, sin fondo, inescrutables y la angustia es una angustia de pesadilla, nacida de un absoluto desconocimiento de las fuerzas en juego. En los primeros hay elementos a-humanos, en los segundos los elementos son simplemente humanos”. Sábato, E., Uno y el universo, Seix Barral, Buenos Aires, 2003, pp. 21 y 22. 
no conducía hacia el cerro del castillo: tan sólo acercaba a él; y luego, como si lo hiciese adrede, doblaba, y si bien no se alejaba del castillo, tampoco llegaba a aproximársele". Pero entonces, ¿qué pasa si ese resplandor o claridad que dimanaba de la puerta de la ley sólo era el brillo del guardián siguiente, y que, al fin, éstos sólo se remiten (y justifican) unos a otros en una cadena circular -autorreferencial- de guardianes que resguardan su propia violencia infundada bajo la luz de un mito (mito del origen, del sentido, de un sentido original)? ¿Qué pasa si, como apuntaron Deleuze y Guattari, en Kafka la ley es incognoscible no porque se retire a su trascendencia, sino simplemente porque carece de toda interioridad, porque está siempre en la oficina de junto, detrás de la puerta, o -como se ve desde el primer capítulo de El proceso- en "el cuarto de al lado" ? ${ }^{34}$ Indagar este "resplandor que, inextinguible, sale por la puerta de la ley" se hace determinante por cuanto es éste el que determina los límites entre fuerza (legalmente justa) y violencia (legalmente injusta).

\section{CREACIÓN EX NIHILO}

En un enigmático texto de 1921, titulado "Para una crítica de la violencia" 35 -Zur kritik der Gewalt, donde Gewalt no sólo es "violencia”, sino también "fuerza legítima”, violencia autorizada, poder legal-, Walter Benjamin hacía ver una hipotética clasificación de la violencia - en torno a la ausencia de su reconocimiento o sanción histórica- para tratar de explicar la obsesión del derecho por el monopolio de la fuerza.

Es sabido $-\mathrm{y}$ esto lo vio con meridiana claridad Paul Ricoeur- ${ }^{36}$ que la fase prohibitiva de la ley no se agota en una dimensión puramente represiva, sino que conlleva asimismo una función estructurante; en nuestro caso, la distinción que permite formular entre violencia autorizada y violencia fuera-de-la-ley. Para Benjamin, los fines que carecen de reconocimiento legal-histórico pueden ser catalogados de "naturales" y los que sí lo tienen, como de "derecho". En lo que concierne al individuo como sujeto de derecho, lo que el orden legal hace es frustrar todos aquellos fines naturales personales que para su satisfacción requieran o se pueda hacer uso de la violencia: "Todo fin natural de las personas individuales colisionará necesariamente con fines de derecho, si su satisfacción requiere la utilización, en mayor o menor medida, de la violencia”. ${ }^{37}$ Pero, ¿es esto sólo

${ }^{34}$ Deleuze, G. y Guattari, F., Kafka. Por una literatura menor, Ediciones Era, México D.F., 1990, p. 68. Explican más adelante: "En consecuencia, es más que nunca necesario renunciar a la idea de una trascendencia de la ley. Si las instancias últimas son inaccesibles y no se dejan representar, no es en función de una jerarquía infinita propia de la teología negativa sino en función de una contigüidad del deseo que hace que todo lo que sucede suceda siempre en la oficina del lado: la contigüidad de las oficinas y la segmentariedad del poder reemplazan la jerarquía de las instancias y la preeminencia del soberano", p. 76.

35 Benjamin, W., "Para una crítica de la violencia" en Para una crítica de la violencia y otros ensayos. Iluminaciones IV, Taurus, Madrid, 2001, p. 26.

${ }^{36}$ Ricouer, P., "La conciencia y la ley. Cuestiones filosóficas”, en Lo justo, Ed. Jurídica, Santiago, 1997, pp. 210 y 211.

${ }^{37}$ Benjamin, Walter, op. cit., p. 26. 
por el peligro de que con ello se puedan abortar fines de derecho y las ejecutivas de derecho? De ninguna manera, piensa Benjamin, pues, de ser así, no se juzgaría la violencia en general sino sólo aquella que se vuelve contra los fines de derecho. Se dirá que un sistema de fines de derecho no logrará sostenerse allí donde fines naturales puedan ser aún perseguidos de forma violenta. Pero eso, aclara, es mero dogma. En este punto Benjamin desliza una posibilidad provocativa, a saber, que el interés del derecho al monopolizar la violencia de manos de la persona particular no exprese intención de defender los fines de derecho, sino, mucho más, al derecho mismo. En otras palabras, "que la violencia, cuando no es aplicada por las correspondientes instancias de derecho, lo pone en peligro, no tanto por los fines que aspira alcanzar, sino por su mera existencia fuera del derecho". ${ }^{38}$ El derecho prohíbe la violencia individual no porque amenaza a tal o cual ley, sino al orden jurídico mismo. Ahora, esto puede parecer una trivialidad tautológica, pero, nos recuerda Derrida, “ ¿no es la tautología la estructura fenomenológica de una cierta violencia del derecho que se establece a sí mismo decretando que es violento, esta vez en el sentido fuera-de-la-ley, todo aquello que no lo reconoce?". ${ }^{39}$ Esta lógica estructura toda fundación de la ley a partir de la cual se producen realizativamente (de manera performativa) las convenciones que garantizan la validez del realizativo gracias al cual uno se da a sí mismo los medios para decidir entre la violencia legal y la violencia ilegal. En este orden de cosas, el Estado no teme el bandidaje o el crimen en cuanto transgreden la ley con vistas a obtener beneficios particulares. El Estado tiene miedo de la violencia fundadora, ${ }^{40}$ capaz de justificar, de legitimar o de transformar relaciones de derecho y, en consecuencia, de presentarse como teniendo un derecho al derecho. ${ }^{41}$ Cuando Rousseau, en el Capítulo III de El Contrato Social, intentó desestimar la trascendencia del "derecho

\footnotetext{
${ }^{38} I d$., pp. 26 y 27.

${ }^{39}$ Derrida, J., "Nombre de pila de Benjamin" en Fuerza de Ley. 'El fundamento místico de la autoridad', p. 86.

${ }^{40}$ Como bien se sabe, en estas páginas Benjamin realiza la distinción entre "violencia fundadora" y "violencia conservadora" de derecho. Según Derrida, la violencia misma de la fundación debe implicar la violencia de la conservación y no puede romper con ella: "Forma parte de la violencia fundadora el que apele a la repetición de sí (...) una fundación es una promesa” (Íd., p. 97). La iterabilidad hace que la violencia fundadora esté siempre representada en una violencia conservadora que respeta sin cesar la tradición de su origen y que no guarda en suma más que una fundación destinada de entrada a ser repetida, conservada, reinstituida.

${ }^{41}$ Uno de los ejemplos que analiza Benjamin en este sentido es el caso de la viabilidad de un derecho de guerra, pues éste resulta de la aprobación, por parte de sujetos de derecho, de una violencia cuyos fines siguen siendo naturales y que, por lo tanto, en casos graves, son susceptibles de entrar en conflicto con sus propios fines de derecho o naturales. Ahora, si bien en un comienzo la violencia bélica acomete sus fines en forma de violencia pirata, se debe precisar que siempre está presente el concepto de "paz", en tanto necesario sancionamiento a priori de cada victoria, independientemente de todas las otras relaciones de derecho. "Y esta sanción consiste en que las nuevas circunstancias son reconocidas como nuevo "derecho". Si se admite la violencia bélica como origen y modelo de toda violencia que persigue fines naturales, entonces todas estas formas de violencia fundan derecho. Y es por ello que se prohíbe a las personas en tanto sujetos de derecho que practiquen una violencia, aunque sólo dirigida a satisfacer fines naturales. Benjamin, W., op. cit., p. 28 y 29 .
} 
del más fuerte", dio con una fórmula que asusta por su precisión: "Desde el momento en que se puede desobedecer impunemente, se puede legítimamente". ${ }^{42}$

Como es evidente, la posibilidad introducida por Benjamin no se articula como un mero desmontaje de las superestructuras del derecho que esconderían y reproducirían a la vez los intereses económicos y políticos de las fuerzas dominantes de la sociedad, sino que lo que busca poner en relieve es que el origen del derecho ya instituido, el momento de fundación mismo de la ley, nunca es un momento inscrito en el tejido homogéneo de una historia, sino que implica siempre una rasgadura del mismo. Como explica Derrida, consiste en una violencia realizativa y por tanto interpretativa, que no es justa o injusta en sí misma, y que ninguna justicia ni ningún derecho previo y anteriormente fundador podría garantizar, contradecir o invalidar por definición: "Ningún discurso justificador -nos dice el filósofo francés- puede ni debe asegurar el papel de metalenguaje con relación a lo realizativo del lenguaje instituyente o a su interpretación dominante". ${ }^{43}$ De aquí que todas las situaciones revolucionarias justifiquen el recurso a la violencia alegando la instauración de un nuevo Estado: "Este derecho por venir legitimará retroactivamente, retrospectivamente, la violencia que puede herir el sentimiento de justicia, su futuro anterior la justifica ya” ${ }^{44} \mathrm{Y}$ es, por lo mismo, que la fundación de todos los Estados -y el orden jurídico que los acompaña- acaece en una situación que se podría llamar "revolucionaria”. Puesto que la constitución del poder es un acto de afirmación existencial hecho por el mismo agente que se está constituyendo, ese momento constitutivo es siempre violento porque -como precisa Fernando Atriasólo puede hacer un "nosotros", en la medida en que haya un "ellos". 45 De esta forma, "Lo que para ellos es aplicación del derecho para nosotros es acto de guerra. Entonces triunfaremos y nos declararemos constituidos (y seremos luchadores por la libertad, patriotas o revolucionarios) o fracasaremos (y seremos criminales o terroristas)". 46 Ahora, con ello obviamente no me refiero a la aserción empírico-descriptiva de que en la génesis de todo Estado se pueden rastrear matanzas o asesinatos, ${ }^{47}$ sino más bien de que siempre, es decir, incluso cuando no tienen lugar esos genocidios, expulsiones o deportaciones espectaculares que acompañan tan frecuentemente a la fundación de los Estados, ${ }^{48}$ éstos se constituyen en violencia.

Esta violencia, se debe decir, no le es extraña al derecho, pero es, en el derecho, lo que suspende el derecho; interrumpe el derecho establecido para fundar otro. Y este mismo momento de suspenso, momento fundador o revolucionario, es, en el derecho, una instancia de no-derecho - "para el derecho la violencia fundacional es siempre

\footnotetext{
${ }^{42}$ Rousseau, J. J., "El contrato social”, en Obras selectas, Edimat, Madrid, 2000, p. 50.

43 Derrida, J., "El derecho a la justicia", p. 33.

${ }^{44}$ Derrida, J., "Nombre de pila de Benjamin”, p. 91.

45 Atria, F., "Sobre la soberanía y lo político", en Revista Derecho y Humanidades, N 12, 2006, p. 70.

46 Íd., p. 71.

${ }^{47}$ Cfr. Copp, D., "The idea of a legitimate State", en Philosophy and Public Affaire, vol. 28, N ${ }^{\circ} 1$,

${ }^{48}$ Derrida, J., “Nombre de pila de Benjamin”, p. 91.
} winter 1999 , pp. 3 y 4 . 
trivialmente criminal", dice acertadamente Atria, y "Por eso el derecho constitucional (a diferencia de la teoría constitucional) no puede comprender el poder constituyente"-. ${ }^{49}$ En ese momento, la fundación del derecho queda "suspendida en el vacío o encima del abismo", dependiendo de un acto realizativo puro, una acción política -con toda la carga de contingencia y arbitrariedad que se pueda leer en ella-, que no tiene que dar cuenta a nadie ni ante nadie. ${ }^{50}$ Hay acá una división política del espacio temporal -división que fuese postulada por Carl Schmitt en sus primeros trabajos, que ciertamente influenciaron a Benjamin-, ${ }^{51}$ en períodos de normalidad/excepcionalidad, y que permite explicar, en definitiva, el acto originario de todo ordenamiento jurídico. ${ }^{52} \mathrm{Y}$ es que, al igual que la decisión soberana de Schmitt -ésta en tanto "principio absoluto" del orden legal-, ${ }^{53}$ el acto fundacional sólo es factible bajo una lógica de excepción, de exterioridad o ruptura con respecto del sistema normativo, del orden legal, de un tiempo de "normalidad" -considerando a la vez, que es este acto violento el que determinará, finalmente, qué es ese orden legal-. ${ }^{54}$ La exterioridad de este momento muestra entonces que la autoridad

\footnotetext{
49 Atria, F., "Sobre la soberanía y lo político", p. 71.

${ }^{50}$ Íd., p. 93.
}

${ }^{51}$ Es conocida la relación intelectual que hubo entre Benjamin y Carl Schmitt, relación que, por lo demás, no le ha sido indiferente a la izquierda. Baste recordar que Adorno y Scholem decidieron no incluir en su compilación de la correspondencia de Benjamin la carta que éste le envió a Schmitt con motivo de su libro Ursprung des deutschen Trauerspiels (1925), en donde reconocía la influencia de las categorías políticas schmittianas en su teoría del arte. Para una revisión somera, aunque un tanto dispersa de esta relación, véase Traverso, E., “'Relaciones peligrosas'. Walter Benjamin y Carl Schmitt en el crepúsculo de Weimar”, en Acta Poetica No 28 (1-2), Primavera-Otoño 2007, pp. 93-109. Vale la pena mencionar acá, la relación que Schmitt sostuvo con otra importante figura de la izquierda, Norberto Bobbio, con quien, después de haberse conocido en Berlín en 1937, mantuvo un intercambio epistolar que duró hasta comienzos de la década de los ochenta. Cfr. Bobbio, N., Autobiografía, Taurus, Madrid, 1998, pp. 167-175. Para una referencia general sobre la influencia de Carl Schmitt en otros autores de izquierda, véase Vásquez, J. I., "La izquierda mira hacia Carl Schmitt”, en Ciudad de los Césares, Año XV No 68, marzo, pp. 27-35.

52 "According to Schmitt, it is logically impossible for the representatives of law and politics to create a limited sphere of time outside the Framework of normality (...) the state of exception must come from the outside. Schmitt thus defines sovereignty as a 'borderline concept (Grenzbegriff), localized in the 'outermost sphere'. Because its place lies beyond the space of normality, sovereignty corresponds to an abnormal time. And, since the framework of normality cannot be broken open from within, the state of exception must be declared by a person coming from the outside who interrupts the line of continuity (...) The state of exception in temporal terms may be described as the cessation of ordinary time". Bredekamp, H., "From Walter Benjamin to Carl Schmitt, via Thomas Hobbes", en Critical Inquiry $\mathrm{N}^{\circ} 25$, Winter 1999 , p. 252.

53 "La decisión soberana es el principio absoluto y el principio no es otra cosa que la decisión soberana". Schmitt, C., Sobre los Tres Modos de Pensar la Ciencia Jurídica, citado en Oro Tapia, L., "Crítica de Carl Schmitt al liberalismo", en Estudios Públicos, N 98, 2005, p. 175.

${ }^{54}$ En su Political Theology, explica: "Every one agrees that whenever antagonisms appear within a state, every party wants the general good-therein resides after all the bellum omnium contra omnes. But sovereignty (and thus the state itself) resides in deciding this controversy, that is, in determining definitely what constitutes public order and security, in determining when they are disturbed and so on (...) After all, every legal order its based on a decision, and also the concept of legal order, which its applied as something self-evident, contains within it the contrast of the two distinct elements of the juristic -norm and decision. Like every other order, the legal order rests on a decision and not on a norm". Schmitt, C., Political Theology Four chapters on the concept of sovereignty, The University of Chicago Press, Chicago, 2001, pp. 9 y 10. 
- de la ley, del Estado- no necesita derecho para crear derecho: Auctoritas, non veritas facit legem, como solía decir Hobbes.

Así, el sujeto realizativo -en muchos sentidos similar al "soberano" de Schmitt- se encuentra ante una ley inexistente, una ley por venir, y es él quien debe fundarla, como todavía por venir, en la violencia. Es, una y otra vez -aunque ahora interpretando al sujeto según la narración de Derrida-, la situación del Vor dem Gesetz de Kafka: el campesino no puede alcanzar la ley, puesto que ésta es trascendente en la medida misma en que es él quien debe fundarla, como todavía por venir, en la violencia. ${ }^{55}$ En consecuencia, la inteligibilidad de esta ley sólo podrá producirla el por-venir; dependerá del orden instaurado/por-instaurar y permitirá interpretar éste. En pocas palabras, una revolución "lograda" producirá los modelos interpretativos apropiados para dar legitimidad a la violencia que produjo esos mismos modelos interpretativos. Y, obviamente, esta legibilidad será tan poco neutra como no-violenta, ${ }^{56}$ a diferencia de lo que pareciese creer en la actualidad el orden y la cultura jurídica chilena.

La ilegibilidad de una violencia -violencia que se lee diaria y mediáticamente como terrorista, femicida, intrafamiliar, tiránica, antisistémica o simplemente inmoral- dependería solamente de la legibilidad de otra violencia, que se articula enunciativamente a sí-misma como "orden simbólico del derecho". Más concretamente, para volver al tema que motivó estas reflexiones, las lecturas de las diferentes esferas del derecho propio indígena-relaciones complementarias de género, procedimientos médicos que no siguen las pautas de la OMS, organización política sobre la base de prestigio o antigüedad, comprensión holística del territorio, justicia comunitaria, etc.- como distintas formas de violencia -violencia de género, atentado contra la vida, régimen de gobierno tiránico, vulneración del derecho de propiedad, infracción a las garantías procesales penales, etc.se basan simplemente en una determinada violencia occidental que se autocomprende y autolegitima como a-política, como esencialmente no-violenta, esto es, fundada en razones trascendentes y objetivas, y por ende superior a las manifestaciones normativas indígenas. En definitiva, podríamos concluir con Žižek, la Verdad o el Significado que uno, en su conducta efectiva, le "transfiere" al hecho -estúpido, traumático e inconsistente- de la Ley ${ }^{57}$ viene a reprimir el hecho básico de que su autoridad no detenta verdad alguna.

\section{CONCLUSIÓN}

Cuenta Plutarco en su Vidas Paralelas que, habiendo sido tomada Roma por los Celtas, acordó Sulpicio - por ese entonces tribuno militar de Roma- con Breno, líder

55 "La ley es trascendente, violenta y no-violenta, puesto que depende más de quién está ante ella -y en consecuencia antes de ella-, de quién la produce, la funda, la autoriza en un realizativo absoluto cuya presencia se le escapa siempre”. Derrida, J., "Nombre de pila de Benjamin", pp. 93 y 94.

\footnotetext{
56 Íd., p. 92.

57 Žižek, S., op. cit., p. 356.
} 
de los Celtas, el pago de mil libras de oro para su liberación. Llegado el momento de su pago, los Celtas comenzaron a engañar con ocasión del peso: primero, con algún disimulo; pero, después, ya abiertamente tirando e inclinando las balanzas. El mismo Breno, con aire de insulto y de burla, quitándose la espada y el cinturón, los puso también en la balanza. Preguntóle Sulpicio qué era aquello, y la respuesta fue: “¿Qué otra cosa ha de ser sino ; ay de los vencidos!?"58

Espero que la argumentación desarrollada a lo largo del presente artículo haga plausible la aserción de que, finalmente, y a pesar de todos los mecanismos ideológicos desplegados para desvirtuar esta interpretación, el principio en el que se "funda" la primacía jerárquica del derecho occidental con respeto al derecho propio indígena, no va más allá en su racionalidad que la exclamación proferida por Breno. El hacer énfasis en este hecho no tiene otra pretensión -no cabe esperar más de la teoría- ${ }^{59}$ que la de hacer consciente al derecho estatal de sus propios prejuicios, de hacerlo consciente -como diría Hans-Georg Gadamer- de su "situación hermenéutica”. Con esto, estimo, se pondría en suspenso la validez de los mentados prejuicios de superioridad, permitiendo así que por fin se pueda "tener noticia de la pretensión de verdad del otro y ofrecerle la posibilidad de que éste se ejercite a su vez". ${ }^{60}$ En otras palabras, el hacer visible el prejuicio de nuestra supremacía epistémica como mero provincialismo o, en el peor de los casos, como pura ideología, abriría un espacio no sólo a la interpelación de la justicia de nuestras creencias, sino a considerar a la otra cultura como un léxico distinto, pero equivalente y, en este sentido, digno de ser considerado en su originalidad.

"Toda constitución tiene una épica, todo decálogo tiene una Escritura", ${ }^{61}$ escribía Robert Cover, enfatizando la importancia de la narración, del mythos que sitúa a todo corpus iuris dentro de una determinada trama de inteligibilidad. ${ }^{62}$ Coherentemente, la desarticulación de la "épica" del derecho que se intentó en este artículo -desarticulación que no es, al fin y al cabo, sino sólo otro tipo de "épica”-, debiese cambiar las formas de creación y lectura de los preceptos que afecten la expresión del nomos indígena. Las consecuencias jurídico-políticas que se deriven de esta nueva narración, si bien no serán la respuesta definitiva a la errática dirección que hasta el momento han tenido las políticas públicas en el tema, creo que permitirían una expresión mayor del derecho propio de los pueblos indígenas, lo que contribuiría obviamente a la consecución de su objetivo autonómico.

58 Plutarco, Vidas paralelas, Ed. Iberia, Barcelona, 1968, Tomo I.

59 "La conclusión general que se sigue de esto es que el modelo en el cual la práctica se altera o modifica por limitaciones traídas de afuera (el modelo del sentido común, por el cual se comprende el cambio) nunca actúa en realidad, y la conclusión que se saca de esa conclusión es lo más polémico de estos ensayos: que la teoría no tiene consecuencias". Fish, S., Práctica sin teoría: retórica y cambio en la vida institucional, Ediciones Destino, Barcelona, 1992, pp. 25 y ss.

${ }^{60}$ Gadamer, Hans-Georg, Verdad y Método, Ed. Sígueme, Salamanca, 1993, Vol. I, p. 370.

${ }^{61}$ Cover, R., "Nomos y narración”, en Derecho, narración y violencia. Poder constructivo y poder destructivo en la interpretación judicial, Gedisa, Barcelona, 2002, p. 16.

${ }^{62} I$ d. , p. 22. 


\section{BIBLIOGRAFÍA}

Aldunate, E., "Interpretación constitucional y decisión política”, en Revista de Derecho, Universidad Católica de Valparaíso, Nº XV, 1993-1994.

Atria, F., “QQué desacuerdos valen? La respuesta legalista”, en Revista Ius et Praxis, Año 8, No 1, 2002.

Atria, F., "Sobre la soberanía y lo político", en Revista Derecho y Humanidades, No 12, 2006.

BARrientos, I., "Licitud del uso y porte de la hoja de coca: un caso de invocación y aplicación judicial del derecho internacional de los derechos humanos", en Defensorías Regionales. Minuta Regional, N $^{\circ}$ 1, mayo, 2008.

BeCA, J. P., "La (im)posibilidad de construir un concepto científico de Constitución”, en Revista Ius et Praxis, año 14, $\mathrm{N}^{\circ}$ 2, 2008.

Benjamin, W., "Para una crítica de la violencia", en Para una crítica de la violencia y otros ensayos. Iluminaciones IV, Taurus, Madrid, 2001.

Biblioteca del Congreso Nacional, Historia de la ley. Compilación de textos oficiales del debate parlamentario. Ley 19.253, Protección, fomento y desarrollo de los pueblos indígenas, Vol. I, Santiago, Chile, 1997.

Bobbio, N., Autobiografía, Taurus, Madrid, 1998.

Borges, J. L., "Kafka y sus precursores", en Obras Completas, Emecé, Buenos Aires, 2007, Tomo II.

Bredekamp, H., "From Walter Benjamin to Carl Schmitt, via Thomas Hobbes", en Critical Inquiry $\mathrm{N}^{\circ} 25$, winter 1999.

Broekman, Jan M., Antropología y derecho, Ed. Civitas, Madrid, 1993.

Butler, J., Lenguaje, poder e identidad, Editorial Síntesis, Madrid, 2007.

Carnevali, R., "El multiculturalismo: un desafío para el Derecho penal moderno", en Política Criminal, $\mathrm{N}^{\mathrm{o}} 3$, 2007. A-6. [http://www.politicacriminal.cl].

Copp, D., "The idea of a legitimate State", en Philosophy and Public Affaire, vol. 28, No 1, winter 1999.

Correa, R., "Informe de Constitucionalidad Convenio 169 sobre pueblos indígenas y tribales en países independientes, de la OIT", en Comisión de Verdad Histórica y Nuevo Trato, Subcomisión de Legislación, 2002.

Cover, R., "Nomos y narración”, en Derecho, narración y violencia. Poder constructivo y poder destructivo en la interpretación judicial, Gedisa, Barcelona, 2002.

Deleuze, G. y Guattari, F., Kafka. Por una literatura menor, Ediciones Era, México D.F., 1990.

Derrida, J., Fuerza de Ley. 'El fundamento místico de la autoridad', Tecnos, Madrid, 2002.

Dumont, L., "The Anthropological Community and Ideology", en Essays on Individualism. Modern Ideology in Anthropological Perspective, University of Chicago Press, Chicago, 1992.

Eberhard, C., "Algunas implicaciones de los enfoques alternativos. Hacia un nuevo enfoque del derecho a través de sus prácticas”, en El otro derecho, ILSA, N 30, 2003.

Fish, S., Práctica sin teoría: retórica y cambio en la vida institucional, Ediciones Destino, Barcelona, 1992.

Foucault, M., La verdad y las formas jurídicas. Cinco conferencias dictadas en la Universidad de Río de Janeiro entre los días 21 y 25 de mayo de 1973. Recurso electrónico, extraído del sitio <www.inicia.es>, visitado el 13 de septiembre de 2008.

Gadamer, Hans-Georg, Verdad y Método, Ed. Sígueme, Salamanca, 1993, Vol. I.

Hubner, R., Martínez, J.C., Lachenal, C. y Ariza, R. (Coord.), Hacia sistemas jurídicos plurales. Reflexiones y experiencias de coordinación entre el derecho estatal y el derecho indígena, Konrad Adenauer Stiftung, Bogotá, 2008. 
KafKa, F., “Ante la ley”, en Relatos completos, Losada, Barcelona, 2006.

Larraín, J., Modernidad Razón e Identidad en América Latina, Ed. Andrés Bello, Santiago, 1996.

Lillo, R., "Pluralismo jurídico en Chile. Formulando un marco teórico para una investigación empírica”, en Lillo, R. (Coord.), Resolución de Conflictos en el Derecho Mapuche, Universidad Católica de Temuco, Temuco, s/f.

Oliva, S., "Reforma procesal penal y ley indígena", en Stippel, J. (Ed.), Reforma a la justicia: una visión de los derechos indígenas, Ministerio de Justicia: Proyecto Reforma Judicial de la Sociedad para la Cooperación Técnica Alemana GTZ-Chile: Ministerio de Planificación, Programa Orígenes, Santiago, 2004.

Oro, L., "Crítica de Carl Schmitt al liberalismo", en Estudios Públicos, No 98, 2005.

Plutarco, Vidas paralelas, Ed. Iberia, Barcelona, 1968, Tomo I.

Reyes Moreno, L. E., "Forma y sustancia en la argumentación en derecho internacional público", en Revista de Derecho, Universidad Austral, Vol. XX, No 1, julio 2007.

Ricouer, P., "La conciencia y la ley. Cuestiones filosóficas”, en Lo justo, Ed. Jurídica, Santiago, 1997.

Rousseau, J. J., "El contrato social”, en Obras selectas, Edimat, Madrid, 2000.

SÁBAto, E., Uno y el universo, Seix Barral, Buenos Aires, 2003.

Salamanca, M., "El derecho en la sociedad mapuche: un análisis de acuerdo a los estudios publicados previos”, en Lillo, R. (Coord.), Resolución de Conflictos en el Derecho Mapuche, Universidad Católica de Temuco, Temuco, s/f.

Sánchez-Castañeda, A., Los orígenes del pluralismo jurídico, p. 475. Documento extraído del sitio <http://www.bibliojuridica.org/libros/4/1855/29.pdf>, visitado el 21 de noviembre de 2008

Santos, B., La globalización del derecho. Los nuevos caminos de la regulación y la emancipación, Universidad Nacional de Colombia, ILSA, Bogotá, 1999.

ShKlar, J., Legalismo, Omeba, Buenos Aires, 1968.

Schmitт, C., Political Theology Four chapters on the concept of sovereignty, The University of Chicago Press, Chicago, 2001.

Traverso, E., “'Relaciones peligrosas'. Walter Benjamin y Carl Schmitt en el crepúsculo de Weimar", en Acta Poetica No 28 (1-2), primavera-otoño 2007.

VÁsquez, J. I., "La izquierda mira hacia Carl Schmitt", en Ciudad de los Césares, Año XV Nº 68, marzo, pp. 27-35.

ŽIŽEK, S., “¿Cómo inventó Marx el síntoma?”, en Žižek, S. (comp.), Ideología. Un mapa de la cuestión, FCE, Buenos Aires, 2008.

Zolo, D., "Una crítica realista del globalismo jurídico desde Kant a Kelsen y Habermas", en Anales de la cátedra Francisco de Suárez, No 36, 2002. 